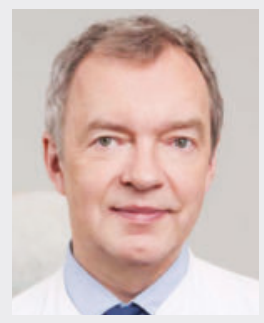

Prof. Matthias Leschke

Klinik für Kardiologie, Angiologie und Pneumologie Klinikum Esslingen $\mathrm{GmbH}$

Akademisches Lehrkrankenhaus der Universität Tübingen

\section{Ist Corona eine Finte, um uns die Freiheit zu nehmen?}

Bill Gates hat das Virus erfunden, um uns beim Impfen Mikrochips zu implantieren. So wird man künftig die Massen steuern. Ein ehemaliger Amtsarzt names Wodarg lacht uns aus, weil wir an Corona glauben. Und einige Arztkollegen teilen seine Meinung! Ja, die Schar der Coronazweifler wächst. Der gefeuerte Radiomoderator Ken Jebsen und der gescheiterte IT-Unternehmer Michael Ballweg führen eine neue Partei an, die "Querdenker“.

Nun, mit der Wahrheit wurde schon immer sehr fantasiereich umgegangen. Auch in den Medien. Doch etwas hat sich grundlegend verändert. Unbequeme Wahrheiten, Tatsachen, Fakten werden im Handumdrehen als Lüge, als bewusste Erfindung einer Elite, als raffiniertes Strategiewerkzeug zur Vernichtung unserer Demokratie, ja der Freiheit schlechthin umgedeutet. COVID-19 als nicht existent, als grandiose Lüge der Regierenden zu entlarven und die Menschen zu Massendemos zu locken, bei denen MundNasen-Schutz und Social Distancing lächerlich gemacht werden - das ist eine Katastrophe.

Die allermeisten Verschwörungstheoretiker sind genuin von dem überzeugt, was sie verbreiten. Sie meinen, der Menschheit einen Dienst zu erweisen, indem sie die Wahrheit ans Licht bringen und einem weltweiten gigantischen Komplott auf die Spur gekommen sind. Und natürlich gibt es auch andere, die das zynisch betreiben, womöglich aus ökonomischen Motiven, weil sie sich erhoffen, so mehr Aufmerksamkeit zu bekommen für ihre Website, mehr Spenden, mehr Klicks und dadurch mehr Werbeeinnahmen.

Eine kontroverse Ansicht muss man nicht unwidersprochen hinnehmen und schon gar nicht diskutieren. „Jeder hat das Recht auf seine eigene Meinung, aber man hat nicht das Recht auf die eigenen Fakten“, das heißt, es muss einen gewissen gesellschaftlichen Grundkonsens geben. Man kann diskutieren, wie man mit der Corona-Krise umgeht, welche Maßnahmen angemessen sind, was zu priorisieren ist. Man kann auch darüber reden, wie gefährlich das Virus wirklich ist, da kann man durchaus auch wissenschaftlich unterschiedlicher Ansicht sein. Aber man kann sich nicht hinstellen und behaupten, dass es das Virus überhaupt nicht gibt oder dass es weniger gefährlich wäre als eine gewöhnliche Grippe. Dazu wissen wir mittlerweile viel zu viel, da gibt es einen breiten Konsens von Wissenschaftlerinnen und Wissenschaftlern aus den unterschiedlichsten Disziplinen überall auf der Welt. Das ist also keine Position, die man ernsthaft diskutieren darf!

Das Internet beschleunigt die Verbreitung von Fake News rasant. Leute, die vielleicht vage Zweifel haben, ob vielleicht irgendwas an dem, was sie in den Mainstream-Medien hören, nicht stimmt, bekommen in den sozialen Medien fragwürdige, jedoch plausibel klingende Erklärungen vorgesetzt. Gleichzeitig denken die Menschen, die diese alternativen Erklärungen glauben, oft, dass diese sehr viel mehr sind, als sie de facto sind. Die Algorithmen dieser sozialen Medien funktionieren so, dass einem ja immer nur Nachrichten vorgesetzt werden, die die eigene Meinung bestätigen.

Medizinische Verschwörungstheorien können dazu führen, dass man sich und andere gefährdet, weil man eben Hygiene- und Abstandsregeln nicht einhält, weil man glaubt, das sei alles Humbug, entweder, weil man sie nicht für wichtig erachtet oder als Akt des zivilen Ungehorsams. Das bedeutet, man kann sich eventuell anstecken, man kann eventuell auch andere dadurch anstecken. Und natürlich kann man dann Leute, die überhaupt noch nicht so sehr darüber nachgedacht haben, die einfach nur sehen, wie sich andere Menschen auf der Straße verhalten und sich anpassen, negativ beeinflussen mit der Konsequenz, dass sie ihre Maske dann auch nicht mehr richtig oder gar nicht mehr tragen. 
Insofern ist das auf eine andere Art und Weise gefährlich wie das Unterminieren des Vertrauens in die Demokratie.

Wir werden diese Pandemie in den Griff bekommen. Daran zweifle ich nicht. Impfstoffe und Medikamente zu finden, ist der Königsweg zur Vernichtung dieses Virus, jedoch brauchen wir die Zeit für eine erfolgreiche Entwicklung von Impfstoffen und Medikamenten. Und aufklären müssen wir die Menschen. Ihnen nichts vormachen. Mal wegzusperren in häusliche Quarantäne und dann wieder laufen lassen, das ist Unsinn und einem hohlen Aktionismus geschuldet. Die Menschen müssen die ganze Wahrheit erfahren. Sie dürfen nicht als unmündige Kinder behandelt werden. Gut, die Verantwortlichen konnten auch nicht wissen, wie sich die Pandemie entwickeln würde. Man hat sicher zu viel abgeschottet. Die Coronaleugner müssen wir jedoch ernst nehmen. Ausgrenzen nützt nichts. Diese Leute mit den verquerten Ansichten könnten unsere Bemühungen um einen wirkungsvollen Schutz vor neuen Infektionen gefährden. 